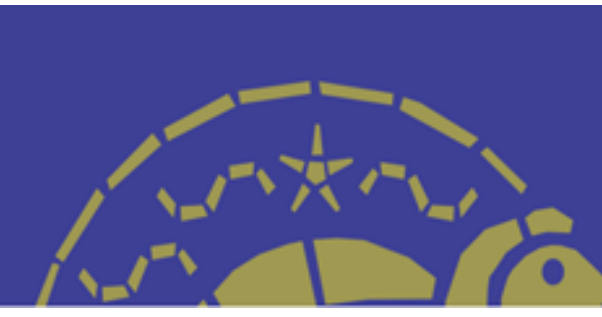

\title{
UMA ABORDAGEM TEÓRICA SOBRE COOPERATIVISMO E ASSOCIATIVISMO NO BRASIL
}

\author{
Djalma Ferreira Pelegrini \\ Empresa de Pesquisa Agropecuária de Minas Gerais - \\ EPAMIG \\ djalma@epamig.br \\ Simone de Faria Narciso Shiki \\ Universidade Federal de São João del Rei \\ sfnshiki@ufsj.edu.br
}

\author{
Shigeo Shiki \\ Universidade Federal de São João del Rei \\ shigeo.shiki@gmail.com
}

\begin{abstract}
Resumo
Este estudo é uma revisão das análises críticas do modelo de desenvolvimento rural brasileiro nas décadas de 1970 e 1980 , em contraponto com as perspectivas atuais. As cooperativas agrícolas representam estruturas que consolidaram o processo produtivo capitalista na agricultura. O objetivo desta revisão é mostrar que as abordagens teóricas da cooperação enfatizam novos conceitos que podem se tornar formas alternativas reais de organização para o desenvolvimento rural. A persistência de condições de subdesenvolvimento em áreas rurais conduziu à busca de alternativas de organização social em nível local e regional, baseadas na solidariedade, na cooperação, e na participação da comunidade. Cooperativas e associações assumem especial relevância novamente, em função do fortalecimento do capital social em uma economia solidária e integrada. Esta visão contrasta com as daqueles que não vêm mais relevância nas ações destas organizações no cenário brasileiro, enquanto enfatiza a importância das cooperativas e das associações para o desenvolvimento rural.

Palavras-chave: Cooperativismo. Associativismo. Desenvolvimento Rural.
\end{abstract}

\section{THEORETICAL APPROACH ABOUT COOPERATIVISM AND ASSOCIATIVISM IN BRAZIL}

\begin{abstract}
This study is a review of the critical analyses of Brazilian rural development model in the 1970s and 1980s, as opposed to the current prospects. Agricultural cooperatives represented structures that consolidated a productive process capitalist in agriculture. The purpose of this review is to show that approaches in cooperation theory emphasize new concepts that might become real alternative forms of organization for rural development. The persistence of underdevelopment conditions in rural areas led to the search for alternatives social organization at local and regional level based on solidarity, cooperation, and community participation. Cooperatives and associations assume again special relevance, due to the strengthening of social capital in a solidarity economy and integrated. This vision is in contrast with those who do not see any relevance in the actions of these organizations in the Brazilian scenario, while emphasizing the importance of cooperatives and associations for rural development.
\end{abstract}

Keywords: Cooperativism. Associativism. Rural Development.

\section{ENFOQUE TEÓRICO DE COOPERATIVAS Y ASOCIACIONES EN BRASIL}

\section{Resumen}

Este estudio es una revisión de los análisis críticos del modelo de desarrollo rural de Brasil en los años 1970 y 1980 , en comparación con las perspectivas actuales. Las cooperativas agrícolas representan estructuras que consolidaron el proceso de producción capitalista en la agricultura. El objetivo de esta revisión es mostrar que los enfoques teóricos de cooperación destacan nuevos conceptos que pueden convertirse en formas reales alternativas de organización para el desarrollo rural. La persistencia de las condiciones de subdesarrollo de las zonas rurales condujo a la búsqueda de las alternativas de organización social en nivel local y regional, basada en la solidaridad, la cooperación y la participación comunitaria. Las cooperativas y las asociaciones son especialmente relevantes de nuevo, debido al fortalecimiento del capital social en una economía solidaria e integrada. Esta visión contrasta con la de aquellos que ya no dan más relevancia a las acciones de estas organizaciones en el escenario brasileño, al tiempo que subraya la importancia de las cooperativas y asociaciones para el desarrollo rural.

Palavras clave: Cooperativas. Asociaciones. Desarrollo Rural. 


\section{INTRODUÇÃO}

A literatura que trata das cooperativas nos países em desenvolvimento ressalta, notadamente, o papel estratégico a elas atribuído no sucesso das políticas de desenvolvimento rural. Desde o início, a via de desenvolvimento cooperativo tem um lugar prioritário nos processos de desenvolvimento. De fato, as agências internacionais, os governantes do mundo em desenvolvimento, os planejadores e os pesquisadores passaram a ressaltar o papel da cooperação e suas instituições na intensificação do desenvolvimento.

As organizações e movimentos associativistas e cooperativistas, tanto nos países industrializados como nos países em desenvolvimento, tomam como referência valores e objetivos convergentes, e se desenvolvem segundo princípios de funcionamento equivalentes. Contudo, os valores atribuídos à cooperativa mudaram com os tempos: eles dependem dos discursos e da estratégia adotada para o desenvolvimento global. Em certos casos, as cooperativas são, com frequência, consideradas como um meio, entre outros, para acompanhar e guiar o desenvolvimento (DEVELTERE, 1998).

O processo de modernização da agricultura, empreendido no Brasil desde meados do século XX, requereu, além da constituição dos complexos agroindustriais, a disponibilização de recursos destinados ao crédito rural, e a implantação de um sistema de pesquisa agropecuária e assistência técnica. A partir dos trabalhos conduzidos em diversas universidades, nos centros de pesquisa da Empresa Brasileira de Pesquisa Agropecuária - EMBRAPA, e nas organizações estaduais de pesquisa agropecuária (OEPAS), procedeu-se à geração e adaptação de tecnologias de produção agrícola (GRAZIANO DA SILVA, 1996; KAGEYAMA, 1990; MÜLLER, 1989).

Nas fases iniciais deste processo, durante as décadas de 1960 e 1970, era premente a necessidade de impingir esforços de melhoria de tecnologias capazes de proporcionar significativos incrementos de produção e produtividade.

Ao extraordinário desenvolvimento da agricultura brasileira durante as décadas de $1970 \mathrm{e}$ 1980, seguiu-se um intenso processo de ampliação do horizonte tecnológico, no âmbito da pesquisa, com base em inovações no domínio das biotecnologias, da microeletrônica, e da automação, que provocaram impactos significativos tanto na reestruturação industrial, como na produção vegetal e animal (GOODMAN et al., 1990; WILKINSON, 1990). A face mais modernizada da agricultura brasileira caracteriza-se, em geral, pela manutenção da estrutura fundiária (modernização conservadora) e pela adoção do padrão tecnológico euro-americano, marcado pela utilização de diversos insumos modernos e incorpora práticas como irrigação, plantio direto e intensa mecanização. Este processo de modernização, no entanto, não foi completo nem 
homogêneo, de sorte que permanece ainda uma outra face de excluídos, que continuaram com suas práticas de cultivo e criação tradicionais, de baixos índices de rendimento e renda.

A organização cooperativa agrária é parte desta estrutura de produção moderna, operando neste mesmo veio agroindustrial, recaindo também sobre ela as críticas ao modelo agroindustrial capitalista. As cooperativas se comportam como qualquer outra empresa capitalista, não dentro de sua própria lógica de cooperação e solidariedade. A cooperativa se tornou um instrumento de submissão dos agricultores à cadeia de produção agroindustrial e agrocomercial.

Entretanto, sob a perspectiva de alguns teóricos contemporâneos, a responsabilidade pela permanência do quadro de subdesenvolvimento e estagnação econômica das áreas rurais recai, em grande medida, sobre as deficiências do sistema de organização social, nos níveis local e regional. Tais autores enfatizam a importância da solidariedade, da cooperação e da participação das comunidades no planejamento e gestão, como atributos necessários para a promoção do desenvolvimento endógeno. Assim, para essa corrente de analistas, as cooperativas e associações assumem especial relevância, em contraste aberto com as posições dos críticos do modelo de desenvolvimento rural brasileiro à ação das cooperativas agropecuárias.

Neste trabalho, pretende-se analisar as contribuições teóricas surgidas nos últimos anos, relativas ao tema das associações e cooperativas agropecuárias, e o papel por elas desempenhado no desenvolvimento rural, em um quadro comparativo com as análises e críticas elaboradas durante as décadas de 1980 e 1990.

\section{O DEBATE TEÓRICO NAS DÉCADAS DE 1980 E 1990}

Nos debates sobre o tema das relações dos agricultores com os demais agentes que compõem os complexos agroindustriais durante os anos 1980 e 1990, enfatizaram-se a condição de subordinação dos interesses dos primeiros perante os setores industriais, agroindustriais e comerciais, no que diz respeito ao estabelecimento de preços, ritmo de adoção de tecnologias, plano de ações etc. Esta percepção é evidente nos trabalhos de Delgado (1985), Müller (1989), Goodman et al. (1990), e Graziano da Silva (1996), dentre outros. Sob esta perspectiva, o processo de agroindustrialização capitalista, conduzido a partir do aporte de recursos tecnológicos e de capital, resultou na diminuição da autonomia e da capacidade de fixação de preços por parte dos agricultores. 
Outros analistas como Tavares dos Santos (1978), Sorj et al. (1982), Paulilo (1990), Matos (1996), dentre outros, enfatizam as condições de subordinação dos produtores integrados ao setor agroindustrial.

Delgado (1985) argumenta que as agroindústrias expropriam dos produtores parte da renda da terra e dos lucros, mediante a imposição de condições de monopólio na determinação de preços industriais, que terminam por deteriorar os termos de troca da agricultura. Contudo observa que o grau de autonomia formal dos produtores integrados é ainda menor que o dos cooperados, pois a estes últimos resta a possibilidade de participar da estratégia de crescimento da empresa ou do grupo econômico a que se ligam como fornecedores.

Para Sorj e Wilkinson (1983), os processos de modernização e agroindustrialização promoveram alterações profundas nas relações sociais na agricultura, de modo que o complexo agroindustrial se transformou no principal beneficiário do sobretrabalho dos produtores agrícolas. Observe-se que, de acordo com Müller (1989), as cooperativas ajudam a compor o núcleo de poder do setor agroindustrial no Brasil. Mais do que isso, para Sorj e Wilkinson (1983), a criação de organizações cooperativas corresponde a uma das estratégias destinadas a promover a reestruturação da base produtiva da agropecuária brasileira, e de integrá-la ao complexo agroindustrial de insumos e maquinarias agrícolas e à indústria de transformação de alimentos e fibras.

As cooperativas se apresentam como mecanismo através do qual o Estado disciplina o pequeno produtor no uso de crédito e insumos modernos, ao mesmo tempo que oferece ao Estado uma organização relativamente fácil de penetrar e manipular, seja pela própria tendência das direções das cooperativas a se desvincular das bases, seja através dos mecanismos materiais e legais pelos quais a cooperativa depende do Estado. (SORJ e WILKINSON, 1983, p.181-182).

Na avaliação de Pinho (1981, p. 12-13),

[...] o próprio sistema econômico capitalista sempre atuou como cerceador do cooperativismo, pela prioridade que concede às empresas capitalistas, em benefício das quais é acionado todo o complexo instrumental de financiamento preferencial, de planos de apoio e de incentivos fiscais.

Desta forma, a linha dominante de interpretação do processo de modernização que vigorou durante as décadas de 1980 e 1990 no Brasil, entendeu a agroindustrializaçao do país como um processo inexorável de aprofundamento da dependência e da subordinação dos agricultores frente ao sistema industrial e agroindustrial, inclusive no que diz respeito ao sistema cooperativista nacional. 
De acordo com Develtere (1998) uma primeira descrição do setor cooperativo requer uma explicação quanto aos sucessos e fracassos concernentes ao desenvolvimento cooperativo, entendendo que, para alguns, a cooperação nos países em desenvolvimento constitui-se em um malogro total, enquanto outros pesquisam os fatores internos e externos que constituem obstáculos ao bom desenvolvimento da cooperação. A maior parte dos estudos explica os malogros como devidos à má gestão, e sugerem ajustes nos processos de engenharia social utilizados para promover ou assistir à promoção e ao desenvolvimento de cooperativas. As estruturas cooperativas economicamente viáveis contradizem a maior parte das teorias sobre as condições preliminares necessárias ao sucesso do desenvolvimento cooperativo. A incapacidade de explicar os malogros e os sucessos decorre principalmente de uma concepção inadequada da relação entre cooperação e desenvolvimento, concepção que tem dominado o discurso e a prática até o presente. O setor cooperativista veicula a herança histórica de diferentes estratégias que lhe foram impostas em diferentes épocas. As sequelas que ele ainda carrega, por vezes intensivas e invasoras, determinam sua capacidade de atender ao estado do movimento cooperativo. Assim, a atividade cooperativa nos países não desenvolvidos é marcada pela interferência do governo na promoção, supervisão e controle do setor. Apesar disso, a promoção de sistemas de cooperação tem sido parte integrante da missão dos governos.

Ainda de acordo com Develtere (1998), o quadro institucional introduzido por efeito das autoridades neocoloniais, e reforçado mais tarde pelas autoridades nacionais, forja o destino do setor cooperativo. Em sua opinião, o papel dos governos deve ser o de reforçar a capacidade dos membros das cooperativas de se tornarem autônomos. Paradoxalmente, a corrente de pensamento dominante, concernente às cooperativas nos países em desenvolvimento, ou mesmo o discurso científico a respeito, insiste afirmando que é possível e vantajoso combinar planificação e ação espontânea, interferência governamental e autossuficiência.

\section{CONTRIBUIÇÕES TEÓRICAS RECENTES}

A produção teórica que emergiu nos últimos anos, mesmo reservando um papel secundário aos fatores de capital e tecnologia, enfatiza a importância da solidariedade, da cooperação e da participação da comunidade no planejamento e gestão, como atributos necessários para a promoção do desenvolvimento. Necessário afirmar, que, na perspectiva recente, a noção de desenvolvimento confere atenção especial para a dimensão social e ambiental, em lugar do crescimento da produção. 
Durante os últimos anos, foram criadas inúmeras associações e cooperativas, em face da convicção de que estas organizações produzem, invariavelmente, efeitos positivos nos níveis local e regional. Estas constituiriam um arranjo favorável à transferência de tecnologias inovadoras, aquisições e comercialização conjunta de produtos, pois empregam metodologias participativas, privilegiando o potencial endógeno das comunidades, associações e cooperativas, podendo, inclusive, desempenhar um papel essencial no desenvolvimento nacional, e mesmo em nível global. Assim, a organização de produtores rurais, em torno de associações e cooperativas, destaca-se dentre as principais estratégias atualmente preconizadas por uma representativa corrente de especialistas que propugna o desenvolvimento rural.

Geralmente, atribui-se às associações, cooperativas e aos empreendimentos de economia solidária, um papel que vai além da viabilização da produção e consumo pelas populações rurais, qual seja o de inserir grupos e comunidades em um ambiente de cooperação e educação participativa, cujos reflexos são reconhecidamente positivos no fomento de processos de desenvolvimento. De acordo com Presno (2009), “as cooperativas, de longa tradição nos países do Mercosul, têm sido vistas, quase sempre, como uma ferramenta de desenvolvimento do meio rural".

Atento a este movimento, o Governo Federal, por intermédio do Ministério do Trabalho e Emprego, tomou a iniciativa de criar a Secretaria Nacional de Economia Solidária - SENAES, em 2003, destinada a implementar o Programa Economia Solidária em Desenvolvimento, com o objetivo de promover o fortalecimento e a divulgação da economia solidária e o desenvolvimento por meio da geração de trabalho e renda com inclusão social (MTE, 2010). Este programa parte de uma visão descentralizada do processo de planejamento, com vistas ao desenvolvimento, apoiando e fortalecendo a formação de redes. Trata-se da disseminação de projetos de cooperação elaborados de forma participativa, incorporando questões culturais e territoriais e fortalecendo práticas autogestionárias.

Segundo Ortega (2008), a incapacidade de promover desenvolvimento a partir do modelo de planejamento centralizado (embora representado pelas políticas desenvolvimentistas), fez emergir, nos últimos anos, a estratégia de descentralização das instâncias decisórias e administrativas governamentais. Desde então, identificam-se duas estratégias de planejamento na perspectiva do desenvolvimento territorial. A primeira, orientada de cima para baixo, em que o desenvolvimento local é planejado pela esfera federal. A segunda, de baixo para cima, quando, por meio da participação das esferas públicas e privadas locais, concebem-se os planos de desenvolvimento local de forma descentralizada. 
Os elementos que levaram a essa alteração do processo de planejamento têm suas origens nas "[...] crises econômica e socioambiental geradas pelos estilos convencionais de desenvolvimento [...]” (MDA, 2004, p.5). O modelo produtivista de transferência do pacote tecnológico da "Revolução Verde", introduzido de cima para baixo, resultou na exclusão social do pequeno produtor e no processo de degradação dos recursos naturais. O fato de não se considerar as especificidades locais resultarou em tecnologias incompatíveis com a situação socioeconômica e cultural do produtor e, também, incompatível com as características biofísicas dos diferentes ecossistemas.

É sabido que o desenvolvimento sustentável almejado pelo país, supõe o estabelecimento de estilos de agricultura, extrativismo e pesca igualmente sustentáveis, que não podem ser alcançados unicamente por meio de transferência de tecnologias. De fato, a transição agroecológica, que já vem ocorrendo em várias regiões, indica a necessidade de resgate e construção de conhecimentos sobre distintos agroecossistemas e variedades de sistemas culturais e socioeconômicos. (MDA, 2004, p.5-6).

Nessa direção, muda-se a concepção de atuação técnica, em prol do planejamento participativo, bem como na intensificação do empoderamento da estrutura social local, que implica em uma assistência técnica que busque o desenvolvimento rural com o uso de metodologias participativas, privilegiando o potencial endógeno das comunidades e territórios, resgatando e interagindo o conhecimento tradicional de agricultores familiares e estimulando o uso sustentável dos recursos locais (MDA, 2004). Essa busca tem sido contemplada na política pública, quando se verifica as Diretrizes da Política Nacional de ATER ${ }^{1}$ :

\footnotetext{
- Promover uma relação de participação e gestão compartilhada, pautada na corresponsabilidade entre todos os agentes do processo de desenvolvimento, estabelecendo interações efetivas e permanentes com as comunidades rurais. (MDA, 2004, p. 7).

- Viabilizar serviços de ATER que promovam parcerias entre instituições federais, estaduais, municipais, organizações não-governamentais e organizações de agricultores familiares e demais públicos anteriormente citados, estimulando a elaboração de planos de desenvolvimento municipal, territorial e/ou regional, assim como a formação de redes solidárias de cooperação interinstitucional.” (MDA, 2004, p. 8).
}

A viabilização do desenvolvimento, por intermédio da participação no planejamento e fortalecimento das redes solidárias de cooperação, coaduna com as mais recentes teorizações, nas quais além do sentido de um processo endógeno, inclusivo e conjuntivo de melhoria das

\footnotetext{
${ }^{1}$ Assistência técnica e extensão rural.
} 
condições sociais, econômicas, tecnológicas e ambientais, o aperfeiçoamento da noção de capital social tem sido grandemente valorizado. "Construir novas instituições propícias ao desenvolvimento rural consiste, antes de tudo em fortalecer o capital social dos territórios [...]" (ABRAmOVAY, 2009, p. 100).

Historicamente, essa construção ocorreu simultaneamente às mudanças estruturais, de ordem econômica e social, ocorridas no mundo nas últimas décadas, que fragilizaram o modelo tradicional de relação capitalista de trabalho. Se por um lado essas transformações repercutiram em aumento da informalidade e precarização do trabalho frente à conjuntura de desemprego, por outro lado, abriu-se um espaço para o surgimento e avanço de novas alternativas de organização do trabalho, com vistas à geração de renda. Experiências coletivas de trabalho e produção vêm se disseminando nos espaços rurais e urbanos, por intermédio de cooperativas de produção e consumo, de associações de produtores, redes de produção consumo e comercialização, instituições financeiras voltadas para empreendimentos populares solidários, empresas de autogestão, dentre outras formas de organização (MTE, 2010). Nesse sentido, as redes têm sido utilizadas para promoção do desenvolvimento rural, a medida que amplia-se a capacidade de atuação em conjunto, elemento caracterizante do fortalecimento do capital social.

De acordo com o MTE (2010), atualmente, a articulação da economia solidária se dá em fóruns locais e regionais, o que resultou na criação do Fórum Brasileiro de Economia Solidária e 27 fóruns estaduais. Além disso, a estruturação da economia solidária ganhou espaço nas esferas governamentais, com crescente apoio dos governos municipais e estaduais, como também de um movimento articulado por gestores públicos interessados em promover trocas de experiências e fortalecimento das políticas públicas de economia solidária.

A realização dos fóruns de economia solidária possibilitou uma melhor articulação entre os membros das redes solidárias e os atores institucionais, em uma construção de baixo para cima. Contudo, esse movimento não alcançou resultados homogêneos nas diversas localidades, dado que persistem grandes variações de capital social entre as localidades. Nem sempre as associações e cooperativas, que são as formas mais comuns, conseguem prosperar e ter essa atuação em prol do desenvolvimento rural sustentável.

Para Santos e Rodriguez (2005) é urgente a tarefa de pensar e lutar por alternativas econômicas e sociais ao modelo dominante neste início do século. "Os sistemas socialistas centralizados não ofereciam uma alternativa emancipatória ao capitalismo, a crise desses sistemas criou a oportunidade para recuperar ou inventar alternativas (no plural) que apontem para práticas e formas de sociabilidade anticapitalistas" (SANTOS e RODRIGUEZ, 2005, p. 25). 
Dentre as alternativas propostas por Santos e Rodrigues (2005) o desenvolvimento de associações e cooperativas destaca-se entre as principais opções, não somente por oportunizar:

[...] remuneração igualitária dos trabalhadores-donos das empresas cooperativas, mas também para a criação de formas de sociabilidade solidárias baseadas no trabalho colaborativo e na participação democrática na tomada de decisões sobre as empresas (SANTOS e RODRIGUEZ, 2005, p. 29).

Presno (2001) considera que as cooperativas constituem alternativas para participação dos produtores no sistema agroalimentar, de maneira que possam obter resultados econômicos satisfatórios, melhores condições de vida e melhor remuneração no preço dos produtos.

Para Santos e Rodriguez (2005, p. 32-33), as associações, cooperativas e demais empreendimentos econômicos solidários dizem respeito a formas de organização compatíveis com o sistema de economia de mercado, cujo papel alternativo diante do processo excludente do capitalismo não é novo. "O pensamento e a prática cooperativista modernos são tão antigos quanto o capitalismo industrial". Tem suas origens no século XIX, quando o pensamento associativista e a prática cooperativa se colocaram como alternativa ao individualismo liberal e ao socialismo centralizado.

Como teoria social, o associativismo é baseado em dois postulados: por um lado, a defesa de uma economia de mercado baseada nos princípios não capitalistas de cooperação e mutualidade e, por outro, a crítica ao Estado centralizado e a preferência por formas de organização política pluralistas e federalistas que deram um papel central à sociedade civil (HIRST, 1994: 15). Como prática econômica, o cooperativismo inspira-se nos valores de autonomia, democracia participativa, igualdade, equidade e solidariedade. (BIRCHALL, 1997: 65; apud SANTOS e RODRIGUEZ, 2005, p. 33).

Apesar da multiplicação do número de cooperativas e da disseminação da teoria associativista, estas não se tornaram alternativas predominantes. "[...] $\mathrm{O}$ cooperativismo deu forma a experiências exemplares de economias solidárias [...] mas não conseguiu converter-se em uma alternativa importante em relação ao setor capitalista da economia nacional e mundial" (SANTOS E RODRIGUEZ, 2005, p. 34).

Dentro da estrutura cooperativista existem elementos de risco, que podem levá-la ao fracasso. Santos e Rodrigues (2005) citam como exemplos desses elementos a própria estrutura democrática, que torna as decisões mais lentas. Além disso, como cada associado tem direito ao voto, isso os impede de obter o nível de capitalização necessário, dado que os investidores desejam que as decisões sejam proporcionais à sua contribuição na cooperativa. Juntamente a 
estes fatores, ainda há a necessidade crescente de investimentos, que acabam na busca por investidores externos, cuja influência desvirtua o espírito da mesma.

Apesar das dificuldades, há uma busca por alternativas mais participativas, o que tem levado a um renovado interesse pelas associações e cooperativas. De acordo com Santos e Rodriguez (2005, p. 35), existem algumas razões para o atual interesse pelas formas de produção solidárias, relacionadas com as condições econômicas e políticas contemporâneas. A primeira razão decorre do fato de que,

[...] ainda que as cooperativas estejam baseadas em valores e princípios não capitalistas [...] sempre foram concebidas, e operaram como unidades produtivas capazes de competir no mercado [...] as cooperativas surgem como alternativas de produção factíveis e plausíveis, a partir de uma perspectiva progressiva, porque estão organizadas de acordo com princípios e estruturas não capitalistas e, ao mesmo tempo, operam em uma economia de mercado. (SANTOS e RODRIGUEZ, 2005, p. 36).

A segunda razão decorre do fato de que as "[...] cooperativas de trabalhadores tendem ser mais produtivas que as empresas capitalistas, porque os seus trabalhadores-proprietários têm maior incentivo econômico e moral para dedicar o seu tempo e esforço ao trabalho [...]" (SANTOS e RODRIGUEZ, 2005, p. 36). Além disso, parecem estar mais adequadas ao mercado fragmentado e volátil da economia global.

A terceira razão é que a difusão das cooperativas estimula o crescimento econômico e diminui os níveis de desigualdade, uma vez que a criação de cooperativas provoca um efeito igualitário direto à distribuição da propriedade na economia, pois os trabalhadores são os proprietários das cooperativas.

A quarta e última razão está relacionada com a geração de benefícios não econômicos para os membros da cooperativa, reduzindo as desigualdades do sistema capitalista. "As cooperativas de trabalhadores ampliam a democracia participativa até o âmbito econômico e, com isso, estendem o princípio da cidadania à gestão das empresas". (SANTOS e RODRIGUEZ, 2005, p. 37).

De acordo com Presno (2009) as características próprias das cooperativas, advindas de seu caráter associativo e gestão democrática, por e para seus membros, diferencia essas organizações dos outros tipos de empresas, especialmente porque concentram problemas singulares.

Apesar dos pontos favoráveis às cooperativas, não basta a sua existência. A coordenação é necessária entre elas e destas com as instituições estatais, para que haja a formação de uma rede de apoio. Nos exemplos de experiências bem sucedidas, a formação dessa rede de apoio é colocada como ponto essencial (SANTOS e RODRIGUEZ, 2005). Nesse sentido, a alternativa 
proposta converge com as colocações iniciais da relevância do movimento em direção ao planejamento participativo, rompendo com o antigo modelo de desenvolvimento de cima para baixo, focado somente no crescimento econômico.

Inúmeras análises teóricas e empíricas, que versam sobre associativismo e cooperativismo, abrangem uma grande variedade de abordagens sobre a perspectiva do desenvolvimento alternativo, reunindo pressupostos e propostas que constituem o alicerce da teoria.

Em primeiro lugar, o desenvolvimento alternativo é formulado com base em uma crítica de fundo à estrita racionalidade econômica que inspirou o pensamento e as políticas de desenvolvimento dominantes. Contra a idéia de que a economia é uma esfera independente da vida social, cujo funcionamento requer o sacrifício de bens e valores não econômicos - sociais, políticos, culturais e naturais -, o desenvolvimento alternativo sublinha a necessidade de tratar a economia como parte integrante e dependente da sociedade e de subordinar os fins econômicos à proteção destes bens e valores. (SANTOS e RODRIGUEZ, 2005, p. 46).

Como discutido na seção 2, alguns autores criticam a insistência sobre novas cooperativas no sentido de que eles somente reforçam o mesmo papel desempenhado pelas empresas no setor agrícola. Bialoskorski Neto (2007, p. 136) considera aceitável a hipótese de que,

[...] conforme o crescimento econômico da organização cooperativa, a lógica do capital suplanta a social e a organização cooperativa passa a operar cada vez mais exclusivamente de acordo com uma lógica apenas de eficiência econômica e do mercado, se afastando cada vez mais das questões de relações sociais, e assim cada vez mais importante será a consideração dos custos de oportunidade do associado para a participação social.

Esta posição é respaldada pelos exemplos de comunidades rurais que optaram pela criação de associações ao invés de cooperativas. Pressupõe-se que as associações constituem estruturas mais flexíveis, desburocratizadas, que pagam menos tributos, e que permitem maior participação dos produtores, características que as tornam mais eficientes.

\section{ECONOMIA SOLIDÁRIA E ORGANIZAÇÕES - nova abordagem para o desenvolvimento cooperativo no brasil}

Os anos 1980 e 1990 marcaram uma era de sucesso para o cooperativismo agrícola brasileiro, tornando-se um dos pilares do crescimento da produção baseado na moderna tecnologia industrial. O processo produtivo, como visto na seção 2, incorporou elementos da produção industrial (semente, pesticida, fertilizante, maquinaria), reduzindo agricultor a uma 
posição subordinado ao e dependente do capital industrial. Este processo foi chamado de agroindustrialização e depois, este setor modernizado tem sido conhecido como setor de agronegócio. As cooperativas se tornaram um ramo do setor de produção industrial e o agricultor o supridor de matérias primas e um mercado cativo de insumos industriais. No setor de grãos, as cooperativas como a COAMO e COOPAVEL, competem com grandes corporações transnacionais e se tornaram parte da poderosa elite do agronegócio.

Esta estória de sucesso, entretanto, não explica a falha experimentada por centenas de cooperativas, assim como as críticas ao movimento cooperativo por sua contribuição ao desenvolvimento e redução da desigualdade social. Este debate oferecido na seção 2, sublinha os seguintes pontos:

a) O processo capitalista de agro-industrialização resultou na redução da autonomia do agricultor e sua capacidade de influenciar preços e o cooperativismo não muda esta posição;

b) A persistência da estagnação econômica e subdesenvolvimento nas áreas rurais refletem, em grande medida, a deficiências do sistema social de organização;

c) A explicação das falhas é devida principalmente à má gestão, mas isto não explica totalmente os casos de sucesso;

d) As dificuldades para explicar as falhas e sucessos são devidos principalmente à inadequada concepção da relação entre cooperação e desenvolvimento.

Assim, cooperativas bem administradas como organização econômicas estão muito bem, mas os benefícios derivados da função social de desenvolver a cooperação e solidariedade, apoio mútuo e a redução da desigualdade não acontecem. As cooperativas que não foram bem sucedidas, tiveram má gestão financeira e operacional, não envolveram os membros associados a exercer seus direitos democráticos, a melhorar seu nível de sociabilidade e de organização social.

O debate do milênio desenvolvido na seção 3, entretanto, evolui, não no sentido de resgatar o movimento cooperativo e associativo, corrigindo suas deficiências, mas integrando-o ao debate mais amplo sobre alternativas de desenvolvimento. Neste último, solidariedade, cooperação e participação comunitária no planejamento e gestão, são necessários atributos para a promoção do desenvolvimento local e regional.

As associações e cooperativas, assim como a miríade de formas de organizações comunitárias reproduzidas ao longo dos anos, para tornar possível a produção e o consumo da população rural, ganharam momento e institucionalização. Grupos sociais e comunidades rurais como um todo são incluídos no ambiente de cooperação e educação participativa, no 
planejamento de ações comunitárias, no reconhecimento do saber local, com resultados não avaliados sobre ganhos de capital social e insumos positivos para o processo de desenvolvimento.

Com a assertiva de que as formas de organização cooperativa enfatizam a gestão do desenvolvimento econômico como um instrumento de sucesso enquanto relega o desenvolvimento social e cooperativo, o fortalecimento das organizações de economia solidária ganha relevância no governo como o Programa Economia Solidária, com ações conduzidas por ONGs e outras instituições como o SEBRAE.

O processo de planejamento do desenvolvimento também ganha relevância, com ações territoriais governamentais, tais como os Territórios da Cidadania (MDA), espaço onde as redes de cooperação solidária são organizadas. Projetos são multiplicados em espaços locais, desenhados com métodos participativos, incorporando questões culturais e fortalecendo práticas de autogestão. O que está em curso é um processo de construção de uma economia baseada na solidariedade, cooperação e participação, deixando para trás a primazia do crescimento econômico. É o capital social que vem primeiro embora a economia permaneça o maior interesse das comunidades. Nesta linha, o desafio é como acumular capital social numa economia de mercado.

No contexto do desenvolvimento territorial e cooperativo, associações e cooperativas e outras formas mais simples de organização, tende a superar dificuldades operacionais, financeiras e gerenciais, aprendendo como trabalhar com as regras de mercado, estabelecidos em leis e regras técnicas. A estratégia é seguir o passo estabelecido pelas experiências anteriores e o processo em curso, isto é, começar com organizações mais simples e aprender fazendo por métodos participativos, e evoluindo para uma organização de mais alta complexidade, na medida em que o capital social é acumulado.

A experiência em associativismo e cooperativismo na microrregião de São João del Rei, em Minas Gerais, pode ser ilustrativa para o entendimento deste processo de construir novas formas de sociabilidade. Nesta região, três cooperativas, a Capermil, a Castil e a Coapro foram desativadas. Informações coletadas em entrevistas com antigos diretores indicam as mesmas causas discutidas neste ensaio, isto é, o péssimo desempenho gerencial e difícil sociabilidade cooperativa.

As principais atividades econômicas destas cooperativas eram a comercialização e industrialização de produtos lácteos e suprimentos de rações e medicamentos veterinários aos membros associados.

A má gestão foi evidenciada por fatores tais como: 
a) Inabilidade em evitar perdas causadas por acidez, conteúdo de antibióticos e água no leite cru;

b) Falta de capacidade gerencial e condução da sociabilidade;

c) Investimentos sem planejamento e apoio técnico;

d) Dificuldades gerenciais no controle de custos operacionais e variação de preços;

e) Dificuldades estruturais no enfrentamento da competição no mercado, especialmente no mercado local de leite.

O resultado final para todas as três cooperativas foi o crescente endividamento e insolvência em diferentes períodos de tempo - de 9 anos (Coapro) a 50 anos (Castil e Capermil). Enquanto a falha do movimento cooperativo é o resultado final, é inescapável dizer que todos eles alternaram períodos de prosperidade e de dificuldade. Os períodos de prosperidade em geral coincidiram com os anos de preços altos de modo estável no mercado lácteo. Em períodos de dificuldades, o problema da participação social dos membros associados, não cooperando com uma decisão dos dirigentes de enfrentar o endividamento, era um deles. Por exemplo, para aumentar os investimentos por meio de cotas necessárias requeriam a adesão da maioria dos membros associados da cooperativa. O estilo centralizado de tomada de decisão, com baixa participação dos membros associados geralmente complicava a adesão. Este estilo centralizado de tomada de decisão pode estar no centro de conflito de interesses e de poder de diferentes grupos de associados que alternavam na diretoria das cooperativas.

Enquanto as cooperativas estavam em estado de insolvência, organizações mais simples como as associações estavam florescendo na região. Esse é o caso das associações de pequenos agricultores e artesãos que se organizavam em torno dos mesmos interesses econômicos, antes associados a cooperativas. Estas associações ganharam apoio de governos municipais, que fortaleceram institucionalmente ao apoiar estruturas regionais como a Associação Regional dos Produtores Associados do Campo das Vertentes (ARPA), localizado em São João Del Rei Minas Gerais. Esta associação regional supre serviços gerenciais e técnicos às associações membro e trabalha como canalizador das demandas comunitárias enquanto agência intermediaria na mobilização de recursos e instituições de apoio como as de extensão rural (Emater), pesquisa agrícola (Epamig), de gestão (SEBRAE) e da Universidade (UFSJ).

Em outra região do Estado de Minas, o Triângulo Mineiro, a principal preocupação da organização associativa é aumentar o poder de negociação do segmento integrado de suínos e aves frente à indústria integradora. Esta preocupação tornou possível ação conjunta de dois grupos de produtores, os da Associação de Suinocultores do Triângulo (AST) e os da Associação 
de Avicultores do Triângulo Mineiro e Alto Paranaíba (AVITAP), que unidos formaram a Associação dos Granjeiros Integrados do Triângulo Mineiro e Alto Paranaíba (AGRITAP).

A AGRITAP, localizada em Uberlândia (MG), age como representante político dos produtores integrados e está conseguindo importantes avanços na negociação com o setor industrial integrador, especialmente com a BRF.

\section{CONSIDERAÇÕES FINAIS}

As mudanças no debate sobre associativismo e cooperativismo no Brasil de $1980 \mathrm{em}$ diante focalizaram na natureza das relações entre cooperação e desenvolvimento. A cooperação se tornou parte de um debate mais amplo sobre desenvolvimento rural não muito distante do passo inicial do 'terceiro setor' entre capitalismo e socialismo. Em um mundo dominado pelas economias capitalistas de mercado, a cooperação é discutida e integrada no que alguns teóricos chamam de economia social. É onde a economia solidária entra no jogo, tanto como reações espontâneas à economia de mercado capitalista socialmente excludente ou encorajado por políticas, tais como o Programa Economia Solidária de desenvolvimento (MTE).

A nova abordagem de cooperação enfatiza a acumulação de capital social, e portanto, os métodos de planejamento de baixo para cima, métodos participativos de construção da sociabilidade são alguns dos instrumentos disponíveis.

\section{AGRADECIMENTOS}

A FAPEMIG pelo apoio financeiro concedido ao projeto.

\section{REFERÊNCIAS}

ABRAMOVAY, R. O futuro das regiões rurais. 2. ed. Porto Alegre: Editora da UFRGS, 2009. ANUÁRIO DO COOPERATIVISMO MINEIRO - 2009. Belo Horizonte: OCEMG, 2009.

BIALOSKORSKI NETO, S. Um ensaio sobre desempenho econômico e participação em cooperativas agropecuárias. Revista de Economia e Sociologia Rural, Rio de Janeiro, v. 45, n. 1, p. 119-138, jan/mar 2007. 
DELGADO, G. da C. Capital financeiro e agricultura no Brasil: 1965- 1985. São Paulo: ÍCONE, Campinas: Editora UNICAMP, 1985.

DEVELTERE, P.. Économie sociale et développement: les coopératives, mutuelles et associations dans les pays en développement. Bruxelles: De Boeck Université, 1998.

GOODMAN, D.; SORJ, B.; WILKINSON, J., Da lavoura às biotecnologias: agricultura e indústria no sistema internacional. Rio de Janeiro: Campus, 1990.

GRAZIANO DA SILVA, J. A nova dinâmica da agricultura brasileira. Campinas: UNICAMP/ I.E, 1996.

KAGEYAMA, A. (org.). O novo padrão agrícola brasileiro: do complexo rural aos Complexos Agro-Industriais. In: DELGADO, G. C.; GASQUES, J. G.; VILLA VERDE, C. M. (Org.). Agricultura e Políticas Públicas. Brasília: IPEA. 1990. p. 113- 223. (Serie IPEA, 127).

MATOS, V. A. Estratégias empresariais no setor avícola: Estudo comparativo de duas regiões produtoras. 1996. 305 f. Tese (Doutorado em economia) - EAESP/FGV, São Paulo, 1996.

MINISTÉRIO DO DESENVOLVIMENTO AGRÁRIO. Política Nacional de Assistência Técnica e Extensão Rural. Brasília, 2004.

MINISTÉRIO DO TRABALHO E EMPREGO. A economia solidária. Disponível em: <www.mte.gov.br/ecosolidaria/sies.asp>. Accesso em: 3 maio 2010.

MÜLlER, G. Complexo Agroindustrial e Modernização Agrária. São Paulo: HUCITEC, 1989.

ORTEGA, A. C. Territórios deprimidos: desafios para as políticas de desenvolvimento rural. Campinas: Alínea; Uberlândia: EDUFU, 2008.

PAUlilo, M. I. S. Produtor e Agroindústria: Consensos e Dissensos. O caso de Santa Catarina. Florianópolis: Editora da UFSC, 1990.

PINHO, D. B. Avaliação do Cooperativismo Brasileiro. 2. ed. (Coleção Ato Cooperativo). Belo Horizonte: FUNDEC, 1981.

PRESNO, N. As cooperativas e os desafios da competividade. Estudos Sociedade e Agricultura, n. 17, out. 2001. UFRRJ, Rio de Janeiro. p. 119-144.

SANTOS, B. de S.; RODRÍGUEZ, C. Introdução: para ampliar o cânone da produção. Tradução de Vítor Ferreira. IN: SANTOS, Boaventura de Sousa (Org.). Produzir para viver: os caminhos da produção não capitalista. 2. ed. Rio de Janeiro: Civilização Brasileira, 2005.

SORJ, B., POMPERMAIER, M. J. e CORADINI, O. L. Camponeses e Agroindústria. Transformação social e representação política na avicultura brasileira. Rio de Janeiro: Zahar Editores, 1982.

SORJ, B.; WILKINSON, J. Processos sociais e formas de produção na agricultura brasileira. In: SORJ, B; ALMEIDA, M.H.T. de. Sociedade e Política no Brasil pós-64. São Paulo: Brasiliense, 1983.

TAVARES DOS SANTOS, J. V. Colonos do vinho. Estudo sobre a subordinação do trabalho camponês ao capital. São Paulo: HUCITEC, 1978.

WILKINSON, J. O futuro do Sistema Alimentar. São Paulo: HUCITEC, 1990. 